\title{
LA AUTONOMÍA DE LA PERSONA FRENTE AL DERECHO A LA VIDA NO INCLUYE EL DERECHO A SER MUERTO POR UN TERCERO: LA SOLICITUD DE ASISTENCIA AL SUICIDIO Y EL CASO DE DIANE PRETTY
}

\begin{abstract}
Ángela Vivanco Martínez*
Resumen: La autora, en la presente monografía, analiza las resoluciones pronunciadas por la House of Lords y por la Corte Europea de Derechos Humanos en el caso de Diane Pretty, ciudadana inglesa fallecida en mayo de 2002 quien, a causa de una enfermedad degenerativa e incurable, pretendió se reconociera inmunidad a su marido en caso de prestarle asistencia para suicidarse. Los fallos examinados rechazaron la solicitud de la recurrente.
\end{abstract}

Palabras clave: Bioderecho, eutanasia, suicidio asistido, autonomía, derecho a la vida

\section{A PERSON'S AUTONOMY VIS-À-VIS THE RIGHT TO LIFE DOES NOT INCLUDE THE RIGHT TO BE KILLED BY A THIRD PERSON: ASSISTANCE REQUEST TO COMMIT SUICIDE AND DIANE PRETTY'S CASE}

\begin{abstract}
The author of this monograph analyses the resolutions pronounced by the House of Lords and by the European Court of Human Rights in the case of Diane Pretty, an English citizen who died in may 2002. Because of a degenerative and incurable disease she pretended her husband be granted immunity if he helped her to commit suicide. The verdicts which were examined rejected her request.
\end{abstract}

Key Words: Biolaw, euthanasia, assisted suicide, autonomy, right to life

\section{A AUTONOMIA DA PESSOA FRENTE AO DIREITO À VIDA NÃO INCLUI O DIREITO A SER MORTO POR UM TERCEIRO: A SOLICITAÇÃO AO SUICÍDIO ASSISTIDO E O CASO DE DIANE PRETTY}

Resumo: Na presente monografia a autora analisa as decisões emanadas pela Câmara do Lordes e Corte Européia de Direitos Humanos no caso Diane Pretty, cidadã inglesa falecida em maio de 2002 que em decorrência de enfermidade degenerativa incurável, pretendeu fosse reconhecida imunidade a seu marido para que a auxiliasse a suicidar-se. As decisões recusaram a solicitação da recorrente.

Palavras chave: Biodireito, eutanásia, suicídio assistido, autonomia, direito à vida

\footnotetext{
* Abogado. Centro de Bioética y Centro de Estudios Jurídicos Avanzados de la Pontificia Universidad Católica de Chile.

Correspondencia: avivancm@puc.cl
} 
El 11 de mayo del presente año 2002 murió, en una institución de cuidados paliativos cercana a Londres, Diane Pretty, mujer inglesa de cuarenta y tres años cuyo caso reabrió uno de los grandes debates bioéticos del presente siglo: la disquisición acerca de si del derecho a la vida puede derivarse una contrapartida representada por el derecho a morir dignamente o bien morir, y si tal cosa puede traducirse en la legitimación del suicidio asistido o de la eutanasia activa voluntaria.

En el presente trabajo analizaremos, en la perspectiva del Bioderecho, los contenidos de los principales fallos pronunciados en el caso Pretty, primero por la House of Lords y luego por la Corte Europea de Derechos Humanos, para examinar posteriormente las connotaciones de éstos en el desarrollo de la actual temática sobre la disposición de la vida humana.

\section{El caso Pretty y los Tribunales de Justicia}

\section{Algunos comentarios introductorios}

El caso de Diane Pretty llegó en última instancia al Tribunal Europeo de Derechos Humanos de Estrasburgo ${ }^{1}$ al recurrir a él la interesada, quien se encontraba paralizada y sufriendo una enfermedad degenerativa e incurable, alegando que la negativa del Director de la Fiscalía Pública del Reino Unido de proporcionar inmunidad a su marido si él la asistía en cometer suicidio y la prohibición del derecho local de dar asistencia al suicidio, infringían sus derechos bajo los artículos 2, 3,

\footnotetext{
1 Texto íntegro del fallo de la Corte Europea de Derechos Humanos en el caso Pretty vs. United Kingdom (Application $n^{\circ} 2346 / 02$ ) dictado en Estrasburgo el 29 de abril de 2002, en inglés y en francés. [Sitio en Internet] Disponible en http:// diariomedico.recoletos.es/asesor/ sentencia020502.pdf Acceso en octubre de 2002
}

8, 9 y 14 de la Convención Europea de Derechos Humanos $^{2}$.

\footnotetext{
2 Conviene recordar las materias a las que aluden cada uno de los artículos de la Convención, esto es, derecho a la vida, prohibición de tortura, derecho al respeto de la vida privada y familiar, libertad de pensamiento, conciencia y religión y prohibición de discriminación, garantías que transcribimos en su texto en inglés:
}

\section{"Article 2 - Right to life}

1 Everyone's right to life shall be protected by law. No one shall be deprived of his life intentionally save in the execution of a sentence of a court following his conviction of a crime for which this penalty is provided by law.

2 Deprivation of life shall not be regarded as inflicted in contravention of this article when it results from the use of force which is no more than absolutely necessary:

a in defence of any person from unlawful violence;

b in order to effect a lawful arrest or to prevent the escape of a person lawfully detained;

c in action lawfully taken for the purpose of quelling a riot or insurrection.

(Nótese que este artículo debe ser leído en conjunción con los artículos 1 y 2 del Sexto Protocolo sobre Derechos Humanos del 28 de abril de 1983, que se pronuncia por la abolición de la pena de muerte, según lo dispone la Sección $1^{\mathrm{a}}$. de la Human Rights Act de 1998 del Reino Unido, invocada por los sentenciadores).

Article 3 - Prohibition of torture

No one shall be subjected to torture or to inhuman or degrading treatment or punishment.

Article 8 - Right to respect for private and family life

1 Everyone has the right to respect for his private and family life, his home and his correspondence.

2 There shall be no interference by a public authority with the exercise of this right except such as is in accordance with the law and is necessary in a democratic society in the interests of national security, public safety or the economic well-being of the country, for the prevention of disorder or crime, for the protection of health or morals, or for the protection of the rights and freedoms of others.

"Article 9 - Freedom of thought, conscience and religion

1 Everyone has the right to freedom of thought, conscience and religion; this right includes freedom to change his religion or belief and freedom, either alone or in community with others and in public or private, to manifest his religion or belief, in worship, teaching, practice and observance.

2 Freedom to manifest one's religion or beliefs shall be subject only to such limitations as are prescribed by law and are necessary in a democratic society in the interests of public safety, for the protection of public order, health or morals, or for the protection of the rights and freedoms of others.

\section{"Article 14 - Prohibition of discrimination}

The enjoyment of the rights and freedoms set forth in this Convention shall be secured without discrimination on any ground such as sex, race, colour, language, religion, political or other opinion, national or social origin, association with a national minority, property, birth or other status". 
En efecto, de acuerdo con la sección 2 (1) de la Suicide Act de 1961 del Reino Unido, si bien se despenaliza el suicidio y se reconoce la autodeterminación en las decisiones de vida y de muerte de la persona, es un crimen asistir a otro para que se suicide ${ }^{3}$. Por tal razón, la requirente había dirigido, con fecha 27 de julio de 2001, una carta al Director de la Fiscalía Pública, solicitándole que no persiguiera penalmente a su marido por ayudarla a suicidarse de acuerdo a sus deseos. Fundaba esta petición en la gravísima disfunción moto-neuronal que padecía, enfermedad sin curación posible, asociada con una pérdida progresiva de la tonicidad muscular que afecta la musculatura voluntaria del cuerpo, hasta llegar a inmovilizar incluso los músculos que controlan la respiración, lo cual conduce a una muerte lenta y angustiosa para el paciente, a la que se encontraba próxima, dado lo muy avanzado de su padecimiento. Ante el miedo de soportar las etapas finales, dolorosas e indignas de su enfermedad, deseaba que se hiciera posible para ella controlar el cómo y cuándo morir evitando tal sufrimiento e indignidad.

Esta petición fue denegada por la autoridad señalada con fecha 8 de agosto del mismo año, fundándose en que no se puede condonar por anticipado la comisión de una ofensa criminal, por más que fueran extraordinarias las circunstancias.

A partir de tal negativa, la paciente se dirigió en apelación judicial, el 20 de agosto, la cual fue rechazada el 17 de octubre de 2001 por la Corte de División, estableciendo que el Director de la Fiscalía Pública no tenía la facultad de declarar que la Suicide Act de 1961 se oponía a la Convención Europea de Derechos Humanos para no aplicarla.

De allí la requirente se dirigió a la House of Lords, la cual denegó su solicitud con fecha 29 de

\footnotetext{
Particularmente, su sección 2 (1), que transcribimos en inglés, dispone: "A person who aids, abets, counsels or procures the suicide of another, or an attemp by another commit suicide, shall be liable on conviction on indictment to imprisonment for a term not exceeding fourteen years".
}

noviembre de 2001, quedándole a la peticionaria como único camino el dirigirse a la Corte de Estrasburgo.

\section{Los fundamentos del fallo de la House of Lords}

El máximo Tribunal del Reino Unido ${ }^{4}$ rechazó la apelación de la señora Pretty de acuerdo con los siguientes fundamentos proporcionados por sus miembros:

\section{a) Lord Bingham of Cornhill}

Lord Bingham inicia su análisis examinando la alegación de la apelante, en el sentido que la prohibición contenida en la Suicide Act de 1961 y la negativa subsecuente del Director de la Fiscalía Pública de evitar perseguir la infracción a ella que se cometería si su marido la ayudara a cometer suicidio, serían incompatibles con el artículo $2^{\circ}$ del Convenio Europeo de Derechos Humanos.

Para estos efectos examina dicha disposición, concluyendo que: "El artículo protege el derecho a la vida y evita que se tome deliberadamente la vida (de otro) salvo en muy determinadas circunstancias. Un artículo con ese efecto no puede ser interpretado en el sentido de conferir un derecho a morir o de solicitar la colaboración de otro para obtener la propia muerte"5. Si bien reconoce que de algunos artículos de la Convención que establecen derechos pueden derivarse derechos negativos como contrapartida (v.g. el derecho de asociación, que implica el derecho a no asociarse, o la libertad de expresión, que contiene el derecho a mantener los juicios o las opiniones en reserva), considera que eso sólo

\footnotetext{
4 The Queen on the Application of Mrs. Dianne Pretty (Appellant) versus Director of Public Prosecutions (Respondent) and Secretary of State for the Home Deartment (Interested Party) 29 NOVEMBER 2001 [2001] UKHL 61: Una transcripción valiosa de los argumentos brindados por los miembros de este Tribunal en este caso se encuentra en el propio fallo de la Corte Europea de Estrasburgo que comentaremos a continuación. [Sitio en Internet] Disponible en http://www.medethics-alliance.org/news/news03.htm Acceso en octubre de 2002.

Ibídem.
} 
se verifica en aquellos artículos en los cuales ese derecho "negativo" no va en contra del derecho mismo que el artículo garantiza. De allí que, si bien algunos pueden considerar que el derecho a la vida lleva aparejada la eutanasia voluntaria, el suicidio, el suicidio asistido por un médico y el suicidio asistido sin la intervención de un médico, ésos no son beneficios que deriven su protección de un artículo enmarcado por la protección a la santidad de la vida.

En este sentido, la pretensión de la apelantede derivar su derecho a morir del derecho a la vida que le garantiza el artículo $2^{\circ}$ ya citado- va en contra de la autoridad de la Convención y también en contra de dos principios del Derecho inglés: En primer término, la diferencia que existe entre el acto de tomar la propia vida y el acto de tomar la vida con la intervención o la ayuda de una tercera persona-el primero es permitido desde que el suicidio dejó de ser un crimen en 1961 y el segundo continúa estando proscrito ${ }^{6}$-; en segundo término, la diferencia entre la cesación de un tratamiento que salva o que prolonga la vida y la acción que puede tener una justificación médica, terapéutica o paliativa, pero que se intenta

\footnotetext{
El propio sentenciador se remite al argumento dado por Lord Hoffmann en el caso Aireadle NHT Trust v. Bland (1993): "human life is inviolable even if the person in question has consented to its violation. That is why although suicide is not a crime, assisting someone to commit suicide is. It follows that, even if we think Anthony Bland would have consented, we would not be entitled to end his life by a lethal injection". Sin embargo, es necesario hacer notar que, en el caso Bland paciente en estado vegetativo persistente respecto del cual su familia pide la desconexión de la sonda nasogástrica que le permitía alimentarse y vivir- la House of Lords, considerando que el tratamiento recibido por el joven no era capaz de beneficiar su actual estado de salud, examina si podía producirle algún tipo de efecto dañoso, concluyendo que la mantención de éste dañaba seriamente su dignidad, al mantenerlo con vida en una situación totalmente indeseable y al no existir interés alguno del paciente relacionado con la mantención de esa vida. Por esta razón, y con el fin de evitar el sufrimiento que para el paciente y su familia podía significar este tipo de vida y considerando que Tony no pudo dejar al respecto una voluntad claramente expresada - ya que su juventud no hacía presumible ponerse previamente en la situación en la que se vio a causa del accidente sufrido-, se autoriza la desconexión de la sonda nasogástrica que se le tenía insertada, produciéndose su muerte a los pocos días. Véase Kennedy I, Grubb A. Medical Law: Text with Materials. London: Butterworths; 1994: 1225 - 6.
}

exclusivamente para poner término a la vida de otro ${ }^{7}$.

A continuación, se dirige a lo aseverado por la apelante, en el sentido que el trato dado a ella infringe el artículo $3^{\circ}$ de la Convención, que prohíbe la tortura y los tratos o penas inhumanos o degradantes. Sobre esta materia, considera que tal cosa se podría configurar si una autoridad prohibiera suministrar analgésicos o drogas paliativas a la señora Pretty, pero lo que se está haciendo es negando inmunidad al señor Pretty si comete un crimen, por lo cual ello no puede interpretarse como una violación del artículo en cuestión. Es más, no existe, de acuerdo con la Convención, una obligación del Reino Unido de suministrar a un paciente terminal que desea, pero al que no le es posible terminar con su vida, la asistencia de otro sin que éste se exponga al riesgo de ser perseguido por dicha acción.

En lo que respecta al artículo $8^{\circ}$, que garantiza el respeto a la vida privada y familiar, Lord

La literatura biojurídica y directamente bioética ha sido muy extensa en cuanto a considerar el rechazo de tratamientos, al menos los desproporcionados, como un derecho del paciente muy distinto a las figuras eutanásicas y de suicidio asistido: "Desde un punto de vista ético no existe... justificación alguna de la imposición de un tratamiento a la persona competente que lo rechaza de forma racional y puede decirse, con Nino, que la misma supondría una muestra de paternalismo identificado con un ilegítimo perfeccionismo estatal coercitivo... Cualquier enfermo competente que no desee proseguir o iniciar un tratamiento por considerar que tal opción favorece un bien altamente valorado por él (su dignidad, tal y como él mismo la entiende) en mayor grado que la contraria (la cual puede consistir, por ejemplo, en el sometimiento a una terapia penosa y prolongada que sólo contribuirá a retrasar su muerte por un determinado período de tiempo)": Tomás C, Lanuza V. La disponibilidad de la propia vida en el Derecho Penal. Madrid: Centro de Estudios Políticos y Constitucionales; 1999: 75. La obra a la que se refiere la autora es de Nino CS. Autonomía constitucional. La Autonomía personal. Cuadernos y Debates. Madrid, Centro de Estudios Constitucionales 1992; 37: 33. En el mismo sentido, en sentencia de 1984, la Corte Constitucional de Colombia precisa que "en términos generales, toda persona tiene derecho a tomar decisiones que determinen el curso de su vida. Esta posibilidad es una manifestación del principio de libertad, consagrado en la Carta de Derechos como uno de los postulados esenciales del ordenamiento político constitucional (Constitución Política arts. 13,16 y 28). Del principio general de libertad emana el derecho específico a la autonomía del paciente que le permite tomar decisiones relativas a su salud", según trascripción en Castaño de Restrepo MP. El consentimiento informado del paciente en la responsabilidad médica. Santa Fe de Bogotá: Temis; 1997: 279. Véase también: Vivanco A. El principio de proporcionalidad terapéutica y el rechazo a los tratamientos médicos. Boletín Científico de la Asociación Chilena de Seguridad 2001; 5 (en imprenta). 
Bingham examina la alegación del abogado de la señora Pretty, en el sentido que dicho artículo garantiza el derecho a la autodeterminación, lo cual incluiría un derecho a decidir cómo y cuándo morir cuando se espera un término de sufrimiento e indignidad, con el que la sección 2 (1) de la Suicide Act interfiere ${ }^{8}$. Sobre dicha garantía, el sentenciador estima que protege la integridad física, moral y psicológica del individuo, incluyendo los derechos sobre su propio cuerpo, pero nada sugiere que incluya el derecho a decidir cómo y cuándo morir ${ }^{9}$.

\footnotetext{
La parte hace remisión expresa al caso de Sue Rodríguez (Rodríguez v. Attorney General of Canada (1994) 2 LCR 136), muy similar respecto de la situación de enfermedad de la señora Rodríguez si se compara con la de la señora Pretty, como, asimismo, hay plena compatibilidad entre lo prohibido por las sección 2 (1) de la Suicide Act inglesa y la sección 241 (b) del Criminal Code de Canadá. En este caso, la peticionaria solicitaba que dicha norma se declarara contraria al Canadian Charter of Rights and Freedoms, que prescribe que sólo se puede privar de la libertad y de la seguridad a una persona de acuerdo con los principios de una fundamental justicia. El tribunal que conoció el caso rechazó la solicitud considerando que "era la enfermedad que la señora Rodríguez sufría y no el Estado o el sistema de Justicia el que le impedía actuar de acuerdo con sus deseos con respecto al tiempo y a la manera de morir". Luego, la British Columbia Court of Appeal consideró por mayoría que si bien la sección 241 (b) del Criminal Code disminuía la seguridad de la que gozaba la requirente de conformidad con la sección 7 del Charter, ello no contravenía los principios de fundamental justicia. Finalmente, en la Supreme Court la opinión fue dividida y la mayoría de los jueces consideraron que la limitación que imponía la norma en comento respecto del suicidio asistido no podía considerarse arbitraria o injusta o de acuerdo con los valores fundamentales en juego en nuestra sociedad. Sin perjuicio de lo anterior, ni aun en el voto de minoría puede hacerse analogía con la Convención Europea de Derechos Humanos, ya que en ella el derecho a la seguridad y a la libertad de la persona sólo aparece en el artículo 5 (1), que no tiene relevancia en el caso Pretty. El artículo 8 no hace referencia a la seguridad y libertad individual, sino que se dirige a la protección de la privacidad y de la integridad física y psicológica. En ese sentido, protege la autonomía personal mientras los individuos viven sus vidas, pero ello no sugiere que el artículo haga referencia a decidir no vivir más tiempo. Sobre el caso Rodríguez, véase Rodriguez V. British Columbia (Attorney General). [Sitio en Internet] Disponible en http:// www.hrcr.org/safrica/freedom_security/rodriguez bc.html Acceso en octubre de 2002.

9 Incluso más. La propia jurisprudencia de la Corte de Estrasburgo en el caso R. v. United Kingdom(1983) 33 DR 270, precisamente sobre la situación de un condenado por auxilio al suicidio, declara: "The Comission does not consider that the activity for which the applicant was convicted, namely aiding and abetting suicide, can be described as falling into the sphere of his private life in the manner elaborated above. While it might be thought to touch directly on the private lifes of those who sought to commit suicide, it does not follow that the applicant's rights to privacy are involved. On the contrary, the Commission is of the opinion that the acts of aiding, abetting, counselling or procuring suicide are excluded from the concept of privacy by virtue of their trespass on the public interest of protecting life, as reflected in the criminal
} provisions of the 1961 Act".
En lo que se refiere el artículo $9^{\circ}$, el sentenciador estima que una garantía respecto de la libertad de pensamiento, conciencia y religión garantiza que la señora Pretty pueda expresar sus firmes creencias acerca de las virtudes del suicidio asistido, pero ello no funda el requerimiento de que su marido sea absuelto de las consecuencias de una conducta que, aunque coincida con las creencias de ella, está prohibida por la ley penal.

Finalmente, respecto del artículo 14 de la Convención, que prohíbe la discriminación, se hace presente que la apelante considera que se la discrimina respecto de otras personas que no están incapacitadas para quitarse la vida sin asistencia de otras. El sentenciador considera que esa argumentación se basa en una apreciación errada, pues la ley no confiere el derecho de cometer suicidio. El suicidio es, como crimen, anómalo, porque es el único crimen en el cual no hay a quien defender. El suicidio, en consecuencia, es despenalizado, porque acarrea un estigma a los inocentes miembros de la familia de quien lo comete y porque son afectados cuando se encuentran que el que intentó suicidarse y no lo logró, es perseguido por no haber tenido éxito. Por ello, la despenalización del suicidio o del intento de suicidio, en 1961, no confiere un derecho a practicarlo, y la ley sigue siendo firmemente contraria a él, como queda en evidencia de la sección 2 (1) de la Suicide Act.

\section{b) Lord Steyn}

Sobre el artículo $2^{\circ}$ de la Convención, sostiene que la interpretación de él va directamente en contra de la pretensión de la apelante en el sentido de poner fin a su vida con la intervención deliberada de otra persona. Nada en el artículo ni en la jurisprudencia de la Corte Europea puede sostener su pretensión.

Sobre los artículos $3^{\circ}$ y $8^{\circ}$, estima que son particularmente inadecuados para derivar de ellos una obligación estatal de asegurar a los 
individuos el derecho a morir con la participación deliberada de terceros.

Respecto del artículo $9^{\circ}$, lo considera perfectamente posible de compatibilizar con medidas de protección impuestas por la ley para tratar el problema de personas vulnerables que pueden ser de otra manera compelidas a cometer suicidio. La lógica de la Convención no implica que la House of Lords deba compeler al Estado a legalizar el suicidio asistido, lo cual debiera ser discutido en una legislatura democrática.

\section{c) Lord Hope of Craighead}

No es función del Director de la Fiscalía Pública permitir que las personas cometan actos que la ley trata como crímenes. No se vislumbra de qué modo rehusar dicha autorización pueda traducirse en un trato inhumano o degradante que atente contra la Convención.

Respecto del derecho a la privacidad, la señora Pretty goza del derecho de autodeterminación; en ese sentido, su derecho a la privacidad es asegurado incluso en la situación de enfermedad terminal que padece, pero eso es enteramente diferente a pensar que de ello se implica una obligación positiva de dar efecto a sus deseos de terminar con su vida por medio de un suicidio asistido.

\section{d) Lord Hobhouse of Woodborough}

La Asamblea Parlamentaria del Consejo de Europa, el 25 de junio de 1999, adoptó un texto que establece la necesidad de proteger la dignidad y la calidad de vida de las personas que fueran pacientes terminales, pero acoge la prohibición presente en contra de tomar la vida de personas enfermas terminales o agonizantes, en concordancia con el artículo $2^{\circ}$ de la Convención Europea de Derechos Humanos y reconociendo que el deseo de un paciente terminal o de una persona agonizante de morir nunca constituye una autorización legal para que muera a manos de una tercera persona.

\section{e) Lord Scott of Foscote}

Comparte las consideraciones de los restantes miembros del Tribunal.

\section{Los fundamentos del fallo de la Corte Europea de Derechos Humanos}

El fallo, luego de transcribir partes relevantes de la resolución de la House of Lords, examina la importancia del derecho interno del Reino Unido -particularmente la Suicide Act de 1961-y de la práctica, citando el famoso caso de $M s B^{10}$. Menciona que, en marzo de 1980, el Criminal Law Revision Committee, en su decimocuarto reporte ("Ofensas en contra de la Persona") revisó la ley relativa a varias formas de homicidio y las penas aplicables a ellas. En la sección F, se discutió el "homicidio por compasión" (mercy killing) $\mathrm{y}$, al respecto, se consideró que, desde el punto de vista práctico, esta figura presenta problemas de definición y puede producir un efecto contrario, es decir, que en vez de evitar el sufrimiento lo cause, al dejar a las personas débiles con una inferior protección de la ley, en comparación con aquéllas que se encuentran sanas y bien.

Luego se cita parte del reporte de la House of Lords Select Committee on Medical Ethics de 31 de enero de 1994, en el cual, si bien los miembros mencionan lo conmovedores que son muchos casos de pacientes terminales con largas agonías y dolores, consideran, sin

\footnotetext{
${ }_{10}$ Ms B. v. an NHS Hospital, Court of Appeal judgement of 22 March 2002. Sobre este caso, puede encontrarse interesante información en: [Sitio en Internet] Disponible en http:// www.guardian.co.uk/letters/story/0,3604,675063,00.html. Acceso en octubre de 2002. Se trata de una paciente terminal que solicita autorización judicial para no proseguir con un tratamiento respiratorio necesario para vivir. Se enfatiza, sin embargo, que se trata de una situación diferente a la de la señora Pretty, pues se plantea el rechazo a una medida de soporte vital por una paciente competente y no el presunto derecho a ser muerta por un tercero.
} 
embargo, que tales argumentos no son suficientes para levantar socialmente la prohibición del homicidio intencional, pues dicha prohibición es la piedra angular del Derecho y de las relaciones sociales. Si bien en algunos casos individuales la eutanasia puede aparecer como lo más adecuado, ellos no permiten razonablemente establecer el fundamento de una política que puede importar severas y graves repercusiones. Más aún, la muerte no es un asunto solamente personal o individual, la muerte de una persona afecta la vida de otras, incluso de maneras y con una extensión que no puede ser prevista. Los miembros del Comité, de acuerdo con ello, consideraron que el tema de la eutanasia es uno de aquellos en que el interés individual no puede ser separado del interés de la sociedad en su conjunto ${ }^{11}$.

Después de hacer estas menciones, que resultan sin duda ilustrativas respecto de la interpretación que hace la Corte acerca de la disponibilidad de la vida, pasa a fijar el contenido preciso del artículo $2^{\circ}$ de la Convención, en el sentido que éste protege el derecho a la vida, sin el cual el goce o disfrute de cualquiera de los demás derechos y libertades garantizados por la Convención, sería ilusorio. Tras fijar las prohibiciones que dicho precepto impone al Estado, de acuerdo con los casos más recientes de su jurisprudencia (Casos Osman v. Turquía y Keenan v. United Kingdom), señala que su redacción no comparte la misma naturaleza que los derechos de libertad. En definitiva aclara, en concordancia con la House of Lords, que el contenido del derecho a la vida no podría ser interpretado, sin grave distorsión del lenguaje, como comprensivo de un derecho diametralmente opuesto: el derecho a morir. De

\footnotetext{
${ }^{11}$ Un extracto bastante completo del reporte señalado puede encontrarse en Keown J, ed. Euthanasia examined: ethical, clinical and legal perspectivas. Cambridge: Cambridge University Press; 1995: 99.
}

esta forma, el máximo tribunal europeo de Derechos Humanos no considera posible deducir del artículo $2^{\circ}$ del Convenio el derecho a morir, sea con la ayuda de un tercero o con la asistencia de una autoridad pública.

En segundo lugar, respecto de la presunta vulneración del artículo $3^{\circ}$-prohibición de tortura y de tratos inhumanos y degradantesque, según la parte requirente estaba representada por las conductas que tuviesen por objeto no evitar la llegada atroz de una muerte irreversible derivada de enfermedad en fase terminal, lo que conduciría a una muerte inhumana, la Corte señala que dicho precepto debe considerarse como una de las cláusulas primordiales del Convenio, en cuya virtud se consagra uno de los valores fundamentales de las sociedades democráticas, signatarias del Consejo de Europa. Agrega que una interpretación del concepto malos tratos o tratos inhumanos o degradantes como el que se sugiere, va más allá de su jurisprudencia y, aunque mantiene un concepto dinámico y evolutivo de la misma, el artículo $3^{\circ}$ debe, sin embargo, interpretarse en relación con el artículo $2^{\circ}$, más arriba expuesto, en el sentido de que no puede obligarse al Estado a proteger los actos que tienen por objeto interrumpir la vida humana.

Luego, la Corte se dirige a la noción de vida privada, señalando que el artículo $8^{\circ}$ protege también el derecho a un desarrollo de la personalidad y a establecer y llevar a cabo las relaciones con otros seres humanos y con el mundo exterior (Caso Burghartz v. Sweden, 1994), si bien precisa que en ningún caso anterior la Corte ha declarado que el artículo $8^{\circ}$ importe un derecho a la autodeterminación en cuanto tal.

Tras ello, la Corte aborda la cuestión nuclear del caso examinado, de la mano de las consideraciones de si el Estado puede recurrir a la protección penal, a través de la tipificación de determinados delitos para prevenir las consecuencias derivadas de la adopción de 
algunos estilos de vida, lo que produciría una injerencia en la esfera privada del individuo ${ }^{12}$.

La Corte enfatiza que la dignidad y la libertad del hombre son la esencia misma de la Convención y, sin negar de ninguna manera la protección de la vida contenida en el artículo $2^{\circ}$, considera que, desde la perspectiva del artículo $8^{\circ}$, la noción de calidad de vida adquiere toda su significación. Agrega que en unos momentos históricos de avance y sofisticación de la Ciencia Médica que permiten un aumento de la esperanza de vida, numerosas personas temen que se les fuerce a vivir hasta una edad muy avanzada o en un estado de grave deterioro físico y mental que les coloque en las antípodas de la percepción de ellos mismos o de su identidad personal. Bajo estas consideraciones y teniendo presente el caso resuelto en 1994 por la Supreme Court de Canadá en el ya citado caso Rodríguez, la Corte admite examinar la queja de la requirente en cuanto a que evitar el poder dar fin a lo que a sus ojos constituye un fin de vida indigno y penoso, implica una vulneración del respeto a la vida privada, tal como queda formulado en el artículo $8^{\circ}$ de la Convención. Para examinar tal vulneración, la Corte señala que el artículo $8^{\circ}$ permite también una injerencia en el ejercicio de un derecho siempre que ello esté previsto en la ley y constituya una medida que, en una sociedad democrática, sea necesaria de acuerdo con los valores que el mencionado precepto declara.

Sobre la base de estas consideraciones de la jurisprudencia de Estrasburgo en torno a los requisitos que hacen legítima una injerencia en el derecho a la vida privada, la Corte, siempre en concordancia con lo resuelto en el caso Rodríguez, establece que los Estados tienen el derecho de controlar, a través de la aplicación del derecho penal general, las actividades

\footnotetext{
${ }_{12}$ Resulta interesante el comentario que hace, en este punto, Manuel Pulido Quecedo en su artículo: Eutanasia y ayuda al suicidio. Caso Pretty c. Reino Unido en Tribuna $\left(\mathrm{RTC} \mathrm{n}^{\circ}{ }^{6}\right)$. [Sitio en Internet] Disponible en http://www.aranzadi.es/ online/areas/penal/artpub/bib_2002_624_rtc6.html Acceso en octubre de 2002.
}

perjudiciales para la vida y la seguridad de terceros, razón por la cual entiende que la disposición de la legislación penal inglesa que condena la ayuda al suicidio (la sección 2 (1) de la Suicide Act de 1961) está concebida e inspirada para preservar la vida y proteger a personas débiles y vulnerables -en especial, la de aquéllas que no están en condiciones de tomar decisiones con conocimiento de causa- contra las actuaciones que traten de poner fin o ayuden a poner fin a su vida. Si bien las personas que padecen una enfermedad en fase terminal varían de un caso a otro, muchas de ellas son vulnerables y es esta vulnerabilidad de las categorías de personas que ellas forman la que constituye la ratio legis de la disposición señalada. La Corte, en esa perspectiva, concluye que la prohibición de suicidio asistido no es una medida desproporcionada.

\section{Bioética y Bioderecho en la Postmodernidad}

\section{La fuerza de la concepción de una "ética privada" contrapuesta a la idea de "ética pública"}

La definitiva consolidación de las sociedades democráticas a fines del siglo XX ha importado un reconocimiento sin paralelo histórico a la libertad del hombre, lo cual no sólo se manifiesta en el orden material o corpóreo (libertad personal, libertad económica, libre acceso al dominio, libertad de contratación, etc.), sino también en el ámbito de la conciencia, en el terreno de las valoraciones $y$, por ende, en el de la ética ${ }^{13}$. El ser

\footnotetext{
${ }^{13}$ Lo cual se vincula de inmediato con el gran desarrollo del principio de autonomía, según el cual, en materia bioética, "es el afectado por la beneficencia o no-maleficencia quien debe autónomamente decidir sobre la conveniencia y oportunidad de actos que atañen principalmente a sus intereses. Bajo ese mismo criterio, le corresponde también evaluar si la omisión o la negativa de ejecutar un acto tiene consecuencias tolerables o un riesgo sustentable”. Kottow M. Introducción a la Bioética. Santiago de Chile: Editorial Universitaria; 1995: 73. En concordancia con los principios descritos por Beauchamp TL, Childress JF, eds. Principles of Biomedical Ethics. New York: Oxford University Press; 1989.
} 
libre para determinar la moral de la conducta, en otras palabras, para ordenarse de acuerdo con los propios principios, ha originado en grandes sectores de la doctrina una firme convicción acerca de la libertad moral individualista, es decir, aquélla que busca la protección de la conciencia y la responsabilidad por la decisión propia $^{14}$, sin intervención de terceros, ni siquiera de quienes esgriman como argumentos los de la protección y salvaguarda de la comunidad. De esta forma, cada uno actuando de acuerdo con sus propios principios e interpretaciones sobre la realidad, respetado y protegido en esa manera de vivir y de proceder, verdaderamente es capaz de aportar al ámbito en el cual se desarrolla, a través de la reflexión, la elección y la competencia de posturas que conlleva la necesaria política de los acuerdos.

El propio sistema democrático intencionadamente soslaya el problema valórico, ya sea por afán de supervivencia, de integración de disidentes o de su imposición como modelo universal. En efecto, el modelo actual fuerza la contraposición de la ética pública y de la ética privada (o individual), considerando a la primera como aquel núcleo de contenidos que, por erigirse en condición de una convivencia plural pacífica, se consideraría jurídicamente exigible y a la segunda como un conjunto de dimensiones omnicomprensivas del bien que cada ciudadano puede privadamente suscribir y que no puede extenderse a los demás ciudadanos, pues significaría una pretensión de imponer sobre éstos creencias ajenas ${ }^{15}$. Si bien tal cosa ha generado

\footnotetext{
${ }_{14}$ Novak M. Morality, Capitalism and Democracy. Londres: IEA Health and Welfare Unit; 1990: 18.

${ }^{15} \mathrm{Al}$ respecto, resulta interesante analizar las tesis contrapuestas de Pesces G, Martínez B. Ética, poder y derecho. Reflexiones ante el fin de siglo. Madrid: Centro de Estudios Constitucionales; 1995 que, como positivista, teme los riesgos de "imponer la ética pública como ética privada y convertir a los ciudadanos en obligados creyentes" (p. 17), y de Ollero Tassara A. "Derecho y Moral entre lo público y lo privado". Estudios Públicos 1998; 69: 25-6, quien considera que "la ética pública, en cuanto marca los criterios que han de organizar la vida social, desborda cuando mucho una dimensión meramente procedimental y formal. Exige determinados contenidos materiales, sin perjuicio que su alcance sea más modesto que el omnicomprensivo de las éticas privadas".
}

un amplio debate, la verdad es que cada vez son más las sociedades en las que crece la exigencia de no intervención alguna del grupo humano en el campo de la ética individual o privada, y en los que se deja limitada la ética pública a lo que Andrés Ollero llama, en perfecta concordancia con las características actuales de la democracia, una ética procedimental, que no señala criterios ni establece conductas obligatorias para alcanzar el bien y que se basa en el carácter trascendente y categórico de la pura racionalidad comunicativa del Hombre ${ }^{16}$.

De allí que el culto por la ética individual y privada se vuelva hacia el pluralismo, el cual se eleva desde hecho sociológico a la categoría ética, como un freno a la pretensión de imponer una sola visión del mundo, haciendo uso opresivo del poder a favor de una determinada concepción ética ${ }^{17}$. Tal cosa deriva en la consideración de una ética individual que obedece a ciertas premisas claramente identificables.

La más relevante de esas premisas consiste en que, dado que el acuerdo valórico es muy difícil de lograr, el sistema social no debe aspirar a más que un consenso procedimenta $1^{18}$, por lo cual la búsqueda de la verdad y del bien fuera de los aspectos formales es tarea estrictamente individual. Tal cosa, sin duda, significa para el pluralismo dirigir el camino de la sociedad hacia el consenso posible en la diversidad.

${ }^{16}$ Ollero Tassara A. "Derecho y Moral entre lo público y lo privado”. Estudios Públicos 1998; 69: 23-4.

${ }^{17}$ Ollero Tassara A. "Derecho y Moral entre lo público y lo privado”. Estudios Públicos 1998; 69: 31.

18 Resulta paradigmática la postura de H. Tristam Engelhardt que hoy se ha convertido en una cita de culto en el ámbito de la Bioética laica: "El principio de autoridad moral subraya la circunstancia de que, cuando Dios no es escuchado por todos de la misma manera, cuando no todos pertenecen a una comunidad claramente definida y estrechamente unida y, ya que la razón fracasa en el intento de descubrir una moral canónica dotada de contenido, la autorización o autoridad moral justificada secularmente no se deriva de Dios, ni de la visión moral de una comunidad moral, ni de la razón, sino de los individuos. En este contexto caracterizado por la "sordera" hacia las palabras de Dios y por el fracaso de la razón, los extraños morales se encuentran como individuos." Engelhardt HT. Los fundamentos de la bioética. Barcelona: Paidós; 1995: 21. 
En esta perspectiva, defender a ultranza que la ética sustantiva resulte patrimonio exclusivo de la individualidad del Hombre, se visualiza como un freno para el poder estatal, ya que la organización política se encontrará impedida de legislar respecto de las conciencias de los individuos, no podrá perseguirlos por sus opiniones ni forzarlos a suscribir normas morales que no compartan, salvaguardándose así la libertad y la dignidad de las personas, ya que, bajo este prisma, tal vez el componente más relevante de aquéllos que conforman el trato digno para con el individuo de la especie humana está constituido por la igualdad en la libertad que antes mencionábamos y que significa ser libre para pensar y actuar de acuerdo con el pensamiento propio.

Por consiguiente, el desarrollo de la Bioética con un sentido casuista, basada en principios operativos más que radicales, tratada como una ciencia de posibles y no de deberes absolutos ${ }^{19}$, importa una base de consenso social respecto de problemas antaño considerados de resolución objetiva por una moral heterónoma y universal, hoy circunscritos a la necesidad de acuerdo social sobre lo aceptable y lo inaceptable, pero teniendo muchas veces en cuenta las circunstancias y sensibilidades particularísimas del caso $^{20}$.

En este sentido, el Derecho y sus distintas ramas siguen una suerte muy similar a la del ac-

\footnotetext{
19 "La postmodernidad pone de manifiesto la imposibilidad de obtener mediante argumentos lógicos una interpretación normativa dotada de contenido de la moralidad y de la bioética que pueda proporcionar autoridad moral a la política pública en general y a la sanitaria en particular... Aunque, desde la perspectiva de una moralidad secular, gran parte de la ética y de la bioética es irremediablemente subjetiva y relativa, existe también un núcleo conceptual secularmente objetivo y absoluto. Existe una estructura intersubjetiva para la ética secular, en virtud de la comprensión misma de la ética como alternativa autoritativa a la resolución de disputas por medio de la fuerza" Engelhardt HT. Los fundamentos de la bioética. Barcelona: Paidós; 1995: 103.

${ }^{20}$ No es casual que los sentenciadores de varios casos con connotaciones bioéticas reconozcan que lo solicitado por el requirente, en algunos casos puede ser "visto" como adecuado, pero que ello no justifica aplicar esa pretensión a todos los casos, habida consideración de los riesgos sociales que tal cosa puede significar. No se trata, en consecuencia, de una definición de lo bueno o de lo malo per se, sino de la selección de ciertas medidas razonables, atendidas las diversas posibilidades casuísticas y teniendo en consideración los riesgos potenciales de la decisión.
}

tual tratamiento de la Bioética y, desde esta perspectiva, son disciplinas hermanadas en la postmodernidad, mucho más de lo que sus cultores separados puedan temer. En efecto, sobre la base antes explicada, la Constitución y, en general, las cartas de reconocimiento de derechos, locales o internacionales, son tratadas -entonces- no como el marco en el que el pluralismo encuentra pautas de desenvolvimiento, sino como parte de la construcción puesta allí precisamente para que ese pluralismo no sea vulnerado, toda vez que el respeto por la individualidad y por la ética individual no se considera un producto social, sino una prerrogativa de la cual debe gozar cada individuo por ser tal, que se superpone a cualquier regulación jurídica -por más alto rango que ésta tenga- a su respecto $^{21}$.

Ello, podríamos decirlo así, sitúa al Derecho positivo en un ámbito de clara subordinación respecto del postulado y de la necesidad de una ética individual y hace del Bioderecho un producto que, más que una juridización de la Bioética, representa una bioetización práctica del Derecho.

\section{La tendencia a la consideración del suicidio asistido y de la eutanasia como derechos}

Las pretensiones de la requirente en el caso que hemos comentado se enmarcan en una tendencia mundial de considerar a tales figuras de disposición de la vida con cooperación, o directamente con intervención de un tercero, como prerrogativas jurídicas garantizadas.

Es efectivo que eutanasia y suicidio representan tópicos que han preocupado a la Filosofía y, después, a la Ciencia Jurídica desde hace cientos de años, pero no es menos cierto que, en el ámbito de la proliferación de derechos que ha tenido lugar a partir de la segunda mitad del siglo XX, han visto el apogeo del debate ya no relativo a su reprobación moral, sino más bien a su despenalización primero $\mathrm{y}$, luego, elevación a rango de garantías en la perspectiva de los nue-

${ }^{21}$ Sobre el tema, Vivanco A. El cuestionamiento del modelo constitucional: una reflexión acerca de la ética individual, los "nuevos derechos" y el regreso a la paradoja de la tolerancia. Revista Chilena de Derecho, Número Especial 1998: 103-13. 
vos derechos o derechos de tercera generación $n^{22}$.

${ }^{22}$ Existen diversas posibilidades respecto de la forma de generación de estos "nuevos derechos". Usualmente constituyen un subproducto de derechos clásicamente reconocidos por las constituciones, de tal manera que se plantean como fragmentaciones de éstos o como resultados de una interpretación muy individual de ellos. Podemos aquí mencionar, por ejemplo, la creación de derechos a la no discriminación arbitraria, definidos por lo negativo respecto de la garantía madre, que claramente es la igualdad ante la ley, y que van tomando distintas características cuando se aplican a la situación de la mujer en materia laboral, a las oportunidades de grupos segregados racialmente o a personas con pocas posibilidades físicas o económicas de participación en sociedades de consumo y altamente competitivas. En otras ocasiones, el nuevo "derecho" no tiene una naturaleza distinta del que lo generó, sino que se puede calificar de "nuevo" porque importa una maximización del derecho de origen, al punto de darle tal carácter de absoluto que le permite superponerse a todo otro derecho e, incluso, ser esgrimido para objetar válidamente toda clase de compromiso jurídico que el sistema exija. En este caso está la libertad de conciencia en su "nueva concepción", que la ha transformado en una garantía emblemática del pluralismo, no, como podría creerse, porque el sistema tradicional no estuviera de acuerdo con que a cada uno respecta determinar su propio pensamiento, juicio y creencia, sino porque hoy se utiliza la libertad de conciencia como un argumento en contra del cumplimiento forzado de los deberes patrios, de la obligación o deber moral de resguardar la propia vida o incluso del deber de socorro, ello sobre la base de que la determinación de lo que es martirio corresponde a cada uno, así como también qué aspectos de las obligaciones que impone un Estado determinado ha de cumplir según sus principios morales. También dentro de este grupo deberíamos incluir a los derechos que se derivan de la libertad de elegir, la cual originalmente se identificaba con materias económicas o contractuales, pero que hoy se traduce en una constante de opciones que el ser humano aborda con el total poder de decisión sobre ellas, sin estar coartado por norma jurídica de ninguna naturaleza y tampoco por una de carácter moral, ya que somete la decisión sólo a su propia ética individual. Ejemplo de ello es el derecho a abortar por parte de la madre o el derecho al tipo de sexualidad que se quiere desarrollar. En otros casos, "nuevos derechos" se crean sobre la base de transformar en garantía constitucional todo aquello que la ciencia posibilita, de tal forma que se produce una identificación entre el poder fáctico y el nacimiento de una facultad amparada por el Derecho. Ello se vincula con la insistencia en la igualdad de acceso a las prestaciones que la Ciencia puede brindar, como también con la estimación de que ciertos procesos vitales en los cuales el individuo está sometido a ciertas leyes o exigencias naturales, pueden abordarse desde perspectivas facilitadas y, por ello, se crea el derecho a realizarlas de manera más cómoda, es decir, se transforman en expresiones de un pretendido derecho al bienestar. En este grupo podemos incluir a los derechos reproductivos, que han pasado desde una situación de dependencia de instituciones tales como la familia o el matrimonio, a ser garantías de carácter estrictamente individual, donde cada uno opta por la oportunidad, forma e incluso técnicas para ejercerlos. Finalmente, un último grupo de estos derechos proviene de las profundas dificultades que ha ocasionado para la Ciencia Jurídica, la confusión civil entre el dominio y la propiedad, respecto de los atributos de la personalidad. Ello ha conllevado un proceso difícilmente detenible y amparado muchas veces por cuantiosos fallos de los tribunales de justicia que han significado la propietarización de tales derechos y la subsecuente creencia que respecto de ellos la persona cuenta con las facultades de usar, gozar y disponer, como si se tratase de un predio. De esta forma, derechos considerados antes absolutos, como el derecho a la vida, han pasado a entenderse patrimonialmente disponibles por su titular, el cual desde luego que puede prescindir de ellos, lo cual ha dado origen a la existencia subsecuente de derechos contrarios, tales como el derecho a la eutanasia y al suicidio asistido.
Sin duda los grandes fundamentos para esta paulatina transformación de figuras punibles en elementos representativos de garantías constitucionales han sido básicamente tres:

a) La lenta imposición del concepto de "calidad de vida" por sobre el de "sacralización o santidad de la vida" ${ }^{23}$.

b) La consideración de que parte de la intimidad o privacidad del hombre representa el ejercicio autónomo de una serie de actos y la toma de decisiones sobre materias tan relevantes como la vida y la muerte ${ }^{24}$.

c) La concepción de que el consentimiento es el gran elemento de justificación de las conductas, al punto de relevarlas de reprochabilidad penal, toda vez que el tercero no actuaría bajo el supuesto del dominio del acto sino como una suerte de instrumento

23 Para Dan Brock existen cuatro componentes que permiten identificar una "buena vida" o vida de "calidad": "1. Funciones primarias (como movilidad y comunicación, que se usan para llevar a cabo casi todos los planes vivenciales); 2 . funciones específicas del agente (que se usan para llevar a cabo un plan vivencial de un agente en particular); 3. satisfacción de los deseos; y 4. felicidad". Brock D. Medidas de la calidad de vida en el cuidado de la salud y de la ética médica. En: Nussbaum MC, Sen A, comp. La calidad de vida. México DF: Fondo de Cultura Económica; 1996: 183.

${ }^{24}$ El Tribunal de distrito estadounidense que conoció en primera instancia del caso "Compassion in Dying v. State of Washington", consideró que las normas que penalizan el auxilio al suicida constituyen una invasión del interés legítimo de las personas que desean que un facultativo coadyuve a su muerte. De acuerdo con este Tribunal, la Decimocuarta Enmienda que protege determinados ámbitos de libertad inherentes a la dignidad y a la autonomía de la persona, utilizada como fundamento en el caso Cruzan, es también aplicable aquí, pues no se puede establecer ninguna distinción entre el hecho de negar un tratamiento de alargamiento de la vida, como ocurría en el caso Cruzan, y el hecho de auxiliar al suicidio de un enfermo terminal, libre y capaz, que lo solicita. Sin embargo, el Tribunal de Apelaciones del Noveno Circuito revocó este fallo, considerando que la ley que penalizaba el auxilio al suicidio no podía estimarse inconstitucional, pues considera las situaciones citadas como no equiparables y al Estado con determinados intereses que proteger, entre otros, el mantenimiento de los profesionales médicos en su papel de sanadores. Este fallo se encuentra comentado en Álvarez Gálvez I. La Eutanasia voluntaria autónoma. Madrid: Dykinson; 2002: 224-5. 
o de herramienta de quien pide ser muerto o ser ayudado a quitarse la vida ${ }^{25}$.

Sin duda que los tres argumentos subyacen en el caso de Diane Pretty y también en otros que se han ido produciendo, con distintos resultados, en los últimos años ${ }^{26}$.

\section{El efecto de tales consideraciones a propó-} sito de estimar estas figuras como derechos, se puede sintetizar como sigue:

\subsection{Creciente confusión entre figuras diferen- tes, pero que tienen ciertos aspectos comunes tales como la eutanasia activa y el suicidio}

${ }^{25}$ La sentencia de la Corte Constitucional de Colombia que, en 1997, postuló la despenalización de la eutanasia, reúne en sus cuatro aspectos principales una muy buena síntesis de los argumentos que se utilizan hoy para postular a la eutanasia y al suicidio asistido como derechos. A saber:

1. "Sólo el titular del derecho a la vida puede decidir hasta cuándo ella es deseable y compatible con la dignidad humana".

2. "El Estado no puede oponerse a la decisión de un individuo que no desea seguir viviendo y que solicita que le ayuden a morir cuando sufre una enfermedad terminal que le produce dolores insoportables, incompatibles con su idea de dignidad".

3. "La actuación del sujeto activo carece de antijuridicidad porque se trata de un acto solidario que no se realiza por la decisión personal de suprimir una vida, sino por la solicitud de aquél que, por sus intensos sufrimientos, producto de una enfermedad terminal, pide le ayuden a morir".

4. "El caso de los enfermos terminales en que concurra la voluntad libre del sujeto pasivo del acto, no podrá derivarse responsabilidad para el médico autor, pues la conducta está justificada".

Véase la trascripción de este fallo y comentario de la autora en Vivanco A. Comentario a la sentencia de la Corte Constitucional de Colombia que despenalizó la eutanasia. En: Boletín Jurídico $n^{\circ} 3$ de la Universidad Europea de Madrid. Madrid: Universidad Europea de Madrid; 2000 (en CD).

${ }^{26}$ Algunos de los cuales hemos tenido la oportunidad de comentar en el artículo: Vivanco A. "Bien Morir: Análisis Critico de Jurisprudencia Constitucional y Penal". Ars Medica. Facultad de Medicina de la Pontificia Universidad Católica de Chile 2000; 2 (2): 83-97. asistido $^{27}$, o el rechazo de tratamientos médicos y la eutanasia pasiva ${ }^{28}$, lo cual sucede par-

${ }^{27}$ Cuando estamos en presencia de la eutanasia solicitada, es decir, de aquélla que se ha venido a clasificar como voluntaria, erróneamente hay quienes la confunden con el suicidio asistido, considerando que se trataría de la muerte que la misma víctima se infiere, utilizando al tercero como una especie de medio o herramienta para lograr su fin. No compartimos este criterio, ya que estimamos que, si bien existen elementos comunes entre la eutanasia y ciertas formas de suicidio asistido, no son lo mismo. Al efecto, resulta conveniente ensayar para ella un concepto operativo, que proponemos como la disposición de la propia vida, consistente en "darse muerte uno mismo, con la activa participación de otro en tal acto, el cual lo asiste y/o facilita la terminación de la vida" (Este concepto pertenece a Smith WJ. Forced Exit. The slippery slope from assisted suicide to legalized morder. New York: Random House: 1997. "A word about terminology", quien aclara que las razones del que ayuda a otro a suicidarse son las mismas, muchas, de quien ejecuta un acto eutanásico). De esta definición quedan claras ciertas diferencias con la eutanasia: Se trata de una figura que consiste en darse muerte uno mismo, es decir, en que la misma persona que muere es la que tiene el control y la propiedad de la conducta; el tercero participa facilitando o cooperando a que la muerte se produzca, pero no causándola; y, por último, las causas que mueven a éste a asistir al suicida pueden ser de naturaleza humanitaria -como en la eutanasia- porque el autor está gravemente enfermo o sufriendo, pero pueden existir otras muy diferentes, como un auxilio prestado a cambio de una retribución económica, o cumpliendo una orden de un superior o de una persona que tiene cierta ascendencia moral sobre éste, etc. En consecuencia, así como el suicida puede tener muy diversas causas para querer quitarse la vida, asimismo quien lo asiste puede tener otras tantas que lo llaman a hacerlo.

${ }^{28}$ Respecto de este concepto hay cierta pugna doctrinaria, ya que, mientras para un sector se trata principalmente de la omisión del tratamiento en que se emplean medios que contribuyen a la prolongación de la vida del paciente cuando ésta presenta ya un deterioro irreversible o una enfermedad incurable en fase terminal, y puede consistir en la no-iniciación de un tratamiento o en suspender el ya iniciado, para otro sector consiste en "la omisión deliberada de tratamientos médicos ordinarios o proporcionados -útiles- que podrían prolongar la vida del paciente y que con su carencia anticipan su muerte", de allí que esta segunda corriente precise que no se trata de "dejar morir" sino de "hacer morir" mediante la precisión apuntada. (Blanco LG. Muerte digna. Consideraciones bioético-jurídicas. Buenos Aires: Ad Hoc; 1997: 31). Las precisiones son importantes: mientras la primera parece confundirse con toda evitación de tratamientos que prolonguen la vida de un paciente terminal, la segunda precisa que la omisión de tratamientos acelera el proceso de muerte del paciente y que los que se evita proporcionarle o le son suspendidos son aquéllos susceptibles de ser calificados como "ordinarios o proporcionados". 
ticularmente en los países en que estas figuras no se encuentran tratadas individualmente, ya sea por falta de legislación adecuada o por encontrarse subsumidas varias de ellas en el tipo general del homicidio, por una parte, o del auxilio al suicidio, por otra. En ellos, la remisión de la discusión directamente al ámbito constitucional, frente a la carencia de un espacio legislativo, a menudo tiende a su tratamiento en conjunto, lo que representa no sólo un error sino además implica consecuencias jurídicas a menudo desafortunadas ${ }^{29}$.

\subsection{Elevación del elemento consenti-} miento $^{30}$, presente en varias de estas figu-

\footnotetext{
${ }^{29}$ Tales situaciones pueden ser coincidentes en cuanto a sus motivaciones, pero no en cuanto al dominio del acto, así como tampoco en cuanto a la participación que cabe al tercero respecto del paciente, que en un caso va a ser víctima, aun con su consentimiento y, en el otro, autor de su propia muerte.

${ }^{30}$ Esta teoría, que opera sobre parámetros propios del Derecho Civil, considera que el consentimiento de la víctima opera como la autonomía de la voluntad en los negocios jurídicos y que, en consecuencia, el paciente concedería al autor un derecho revocable a realizar la acción típica la cual estaría desprovista de antijuridicidad, en razón que el ejercicio de un derecho no podría ser contrario al ordenamiento jurídico. La tesis en comento ha sido sostenida por algunos autores en Chile, ya que si bien el Derecho Chileno no contempla en sus normas positivas al consentimiento como causal de justificación de una conducta típica, un sector de la doctrina, siguiendo tendencias del Derecho Comparado, la ha estimado como causal de justificación supralegal, lo cual es discutido por autores como Alfredo Etcheberry ("tratándose de los delitos contra la vida, el bien jurídico protegido es considerado "no disponible", por el interés social comprometido en su conservación." Etcheberry A. Derecho Penal. Parte Especial. Santiago: Editorial Jurídica de Chile. $3^{\text {a }}$. Edición revisada y actualizada; 1997: 41), particularmente a propósito del derecho a la vida como bien jurídicamente protegido. Sin embargo, para otros autores, incluso el derecho a la vida es renunciable en ciertas circunstancias, ya que la manifestación de voluntad en orden a disponer de su vida por parte del paciente terminal, por ejemplo, tendría un fundamento en el hecho de situar a la libertad y, en consecuencia, a la decisión autónoma del sujeto, en la cúspide de los valores del ordenamiento jurídico, debiendo "interpretar todos los derechos fundamentales de la persona como emanaciones del derecho al libre desarrollo de la personalidad o, si se prefiere, de la dignidad de la persona humana." (Véase: Cobo Del Rosal M, Carbonell Mateu JC. Derecho Penal, Parte Especial. Valencia: Tirant lo Blanc; 1988: 548 9 ). De esta forma, el derecho individual a una determinada calidad de vida, implicaría un derecho a decidir también sobre la oportunidad, forma y circunstancias de la muerte, cuando la vida ya no es más deseada.
}

ras, hasta transformarse en una causal, ya sea de justificación frente a la existencia de conductas punibles o directamente de ausencia de la tipicidad, lo cual deja de lado una vasta gama de reflexiones acerca de la responsabilidad ética y jurídica del agente, sin perjuicio de la participación de la propia víctima en la decisión acerca de su muerte.

\section{Los aportes que representan los fa- llos examinados en el caso de Diane Pretty}

En el escenario de una creciente despenalización, sea por vía constitucional, legislativa o directamente jurisprudencial, de las figuras que implican de uno o de otro modo una disposición de la vida humana, todo ello combinado con la evidente justificación de ellas por la vía de estimarlas manifestaciones de los derechos de las personas, la jurisprudencia del caso Pretty resulta altamente destacable, aunque no exenta de dificultades.

Conviene destacar la claridad con la que aborda la relación entre el derecho interno inglés y la Convención Europea de Derechos Humanos, tarea de compatibilización que usualmente reviste una problemática propia para los Tribunales de Justicia en tiempos globalizados. En ese sentido, fija adecuadamente los alcances de los artículos citados de la Convención en orden a su aplicación directa sobre el Derecho inglés, con las siguientes precisiones:

1. La despenalización del suicidio efectuada por la Suicide Act de 1961 no ha significado su transformación en una conducta jurídicamente valorada o un derecho que sea la contrapartida del derecho a la vida, sino que implica una decisión de política criminal destinada a evitar acrecentar el daño y el sufrimiento de la propia persona 


\section{que intenta suicidarse o de su familia ${ }^{31}$.}

2. Tal situación importa o representa una subsistencia de la reprochabilidad del suicidio, particularmente para quien participa en él auxiliando a un tercero, ya que a menudo no se encuentra condicionado, como lo está quien decide su propia muerte, por dolores o sufrimientos insoportables y, además, porque existe un deber general de preservación de la vida humana que no sólo ignora sino que derechamente infringe. Tal cosa es una de las razones para sostener la validez de la sección 2 (1) de la citada Suicide Act ${ }^{32}$.

\footnotetext{
31 Postura diametralmente opuesta a la que pretende hacer del suicidio una manifestación jurídica del derecho a la autonomía y, en consecuencia, una conducta plenamente validada constitucionalmente. En este sentido, véase: Jiménez de Asúa L. IV Tratado de Derecho Penal. Buenos Aires: Editorial Losada; 1976: 639-59, quien señala que la impunidad del suicidio no se basa en una derogación de los principios según los cuales el hombre no puede consentir en ser privado de la vida porque ésta es un bien de cuya titularidad no puede disponer, sino en razón de que el sujeto que lo hace es incapaz de sentir la pena e imponérsela si yerra la autoagresión. Confróntese, en sentido contrario: Gimbernat Ordeig E. Eutanasia y derecho penal. En: Estudios de Derecho Penal. Madrid: Tecnos; 1990: 50, quien considera que la despenalización del suicidio se justifica, particularmente en el caso de pacientes que sufren, no en una razón de política criminal sino porque se renuncia, mediante una facultad constitucional, a un bien devaluado del que se goza asimismo en virtud de la Constitución. Considera que el valor sacrificado (vida) es una vida devaluada "en cuanto a que su titular renuncia a ella, en cuanto a que su final está próximo y/o se ha convertido en un padecimiento físico, y en cuanto a que, por consiguiente, muchas veces es incompatible la coexistencia de los dos derechos garantizados por el mismo artículo $15 \mathrm{CE}$ : el derecho a la vida y el derecho a no soportar tratos inhumanos".

32 No podemos dejar de señalar que este argumento de la Corte es uno de los más controvertidos, fundamentalmente por dos razones. La primera, por el elemento "misericordia" o "piedad" que puede estar presente en el auxilio al suicidio y que lo asemeja con la figura de la eutanasia, de tal modo que quien actúa lo hace, asimismo, condicionado o movido no quizás por su propio sufrimiento, pero sí por el sufrimiento del otro. La segunda, es la objeción jurídica que nos parece altamente relevante y que se expone muy adecuadamente en Núñez Paz MA. Historia del Derecho a morir. Oviedo: Editorial Forum S.A.; 1999: 151, en cuanto a que la penalización del auxilio al suicidio importa una suerte de absurdo jurídico, pues mantiene punible la participación -en calidad de cómplice- de una persona en una figura que no es delictual para su autor. $\mathrm{Si}$ bien nos parece que la clave de la respuesta puede encontrarse en que la reprochabilidad de la ayuda al suicida sólo puede hacerse valer respecto de quien la practica, si el suicida obtiene su propósito de morir, de tal modo que la conducta se mire como punible, pero sólo sea posible aplicar sanción al cómplice por estar muerto su autor, ello no evita que respecto a este punto sea necesario preguntarnos la procedencia misma de la figura penal.
}

3. Sin perjuicio de que las garantías del propio Derecho interno inglés, así como de la Convención Europea de Derechos Humanos, protegen la privacidad y la libertad de conciencia de las personas, los fallos en estudio, asimilando las argumentaciones dadas en el caso de Sue Rodríguez en Canadá, destacan que éstas pueden ser limitadas en aras de las necesidades propias de proteger ciertos valores fundamentales por parte del Estado, como es el caso de la vida humana, la que es prioritario conservar, por lo cual legalizar la asistencia a la decisión de muerte de un ser humano puede representar una facilitación a la muerte de personas débiles o enfermas, que se ven compelidas a ello no por una genuina decisión, sino por soledad, abandono e incluso la presión de quienes los cuidan ${ }^{33}$.

4. Se hace énfasis por los sentenciadores, en coordinación con el Derecho inglés, que debe distinguirse claramente la facultad que tiene una persona competente de rechazar tratamientos médicos, incluso vitales, de la colaboración directa en darle muerte, ya que en un caso se trata de una decisión propia de la paridad actualmente reconocida en la relación médico-paciente y de la valoración del principio de calidad de vida frente a tratamientos gravosos, desproporcionados o inútiles, mientras que en el segundo caso hay una acción directamente encaminada a dar muerte a un individuo ${ }^{34}$.

\footnotetext{
${ }^{33}$ Esta opinión es plenamente coincidente con lo señalado en Washington et al. versus Glucksberg, 1997, en el cual la Suprema Corte de los Estados Unidos declara directamente como interés del Estado "prevenir el suicidio, estudiarlo, identificarlo y tratar sus causas... Legalizar el suicidio asistido puede hacer más difícil para el Estado proteger a personas deprimidas o mentalmente enfermas o a quienes son víctimas de dolores no tratados, respecto de sus impulsos suicidas". Esta sentencia se encuentra transcrita en Uhlmann MM, ed. Last Rights. Assisted suicide and euthanasia debated. Michigan: Eerdmans; 1998: $600-29$.

${ }^{34}$ La sentencia de la Suprema Corte de los Estados Unidos dictada en el caso de Vacco (General Attorney, State of New York) v. Quill, distingue, precisamente, entre dejar morir a un paciente y causar la muerte de éste "ya que es un derecho del paciente rehusar tratamientos médicos que interfieren en sus decisiones prioritarias, pero no existe derecho y aún más, se penaliza por las leyes de la mayoría de los Estados, el asistir a otro para que se suicide". Fallo transcrito en Uhlmann MM, ed. Last Rights. Assisted suicide and euthanasia debated. Michigan: Eerdmans; 1998: 630 - 633 .
} 
5. Finalmente, la Corte Europea de Derechos Humanos se aparta de las tendencias legislativas que han tenido su concreción durante el año 2002, con la definitiva despenalización de la eutanasia en Holanda y con la condicionada despenalización que se ha aprobado legislativamente en Bélgica, en cuanto a aclarar específicamente que el homicidio "piadoso" o eutanasia directa no resulta aceptable, no sólo en aras del valor de la vida humana protegida por una prioridad estatal, sino en orden a que una situación como ésa no puede ser validada por el Derecho, en el sentido que se constituye directamente en una acción homicida, con pleno dominio del acto por parte de quien la ejecuta, y respecto de la cual el consentimiento del paciente -al igual que en el caso de la solicitud de colaboración al suicidio- puede fundamentarse, más que en una decisión libre que signifique la plenitud del ejercicio de garantías constitucionales, en una situación de desmedro, debilidad o abandono.

Se previene, de este modo, en los fallos que hemos analizado y que son plenamente coincidentes entre sí, respecto del peligro de pendien- te resbaladiza que puede implicar la legalización de la disposición de la vida solicitada a un tercero, ya que tal solicitud puede, en definitiva, terminar siendo supuesta, presumida $\mathrm{o}$, incluso, reemplazada por la voluntad de ese tercero o por las decisiones del Estado acerca de qué vidas conviene o no preservar.

Creemos que tales prevenciones resultan útiles de hacer, particularmente en el medio de nuestros países latinoamericanos, los cuales, por carecer habitualmente de legislación sobre esta materia, son a menudo destinatarios de propuestas legislativas que pretenden mostrar una interpretación del derecho a la vida casi unilateralmente asociado con la validación del derecho a morir como una contrapartida necesaria. Si bien no puede ignorarse que, en algunos casos, la muerte se puede presentar como una solución piadosa -luego de tanto penar, como diría Miguel Hernández- ha de tenerse la debida precaución de que esa solución no pueda transformarse en lo contrario de la autonomía, esto es, en el extremo dirigismo estatal respecto a cómo terminar con la vida humana subvalorada frente a la enfermedad y al dolor. 